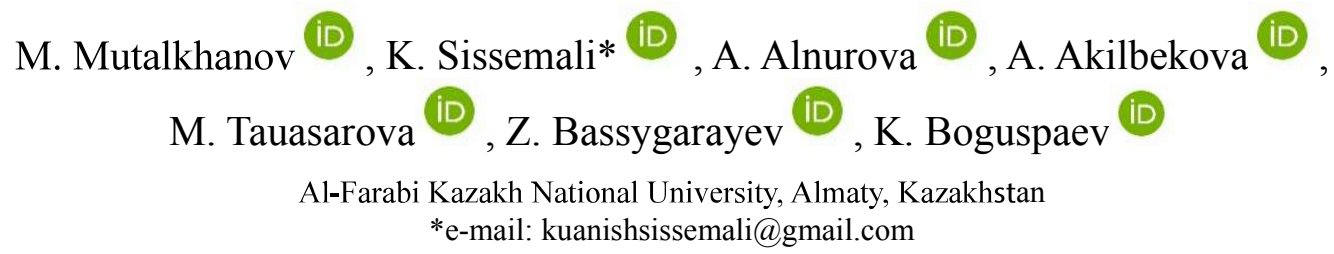

\title{
Determination of the correlation between the accumulation of pigments and natural rubber in Tau-saghyz
}

\begin{abstract}
Natural rubber is a valuable polymer used in a wide variety of industries, from tire manufacturing to medical products and applications in the food industry. The tau-sagyz rubber plant (Scozonera tausaghyz Lipcsh et Bosse) is one of the few plants in the world that can be used in the production of natural rubber when cultivated in culture. To increase the productivity of plants, it is necessary to establish factors affecting the biosynthesis of natural rubber. In our studies, the level of pigments (chlorophyll-a, b, carotenoids) was chosen as a factor that may have a positive effect on the accumulation of rubber in the roots of S. tau-saghyz. For this purpose, samples (leaves, roots) were taken from 3 groups of plants (north, south, east) in the Karatau mountains of the Kurman-Tas range. The extraction of pigments from leaf samples was carried out with acetone, and the extraction of rubber from the roots was carried out with hexane. The obtained data on the content of pigments and rubber in the samples were statistically processed using the t-test and Pearson correlation analysis. As a result, a statistical difference in the values of pigment accumulation in leaves and rubber in roots between the 3 studied groups of plants is shown. On the other hand, a very low level of correlation was found between the accumulation of pigments in the leaves and rubber in the roots in all three groups. The obtained results reliably showed that the level of pigment accumulation in the leaves does not affect the accumulation of rubber in the roots of Tau-sagyz.
\end{abstract}

Key words: Tau-saghyz, pigment accumulation, natural rubber, correlation.

\section{Introduction}

The importance of development of alternative crops for the natural rubber production. Natural rubber (NR) is a high molecular weight polymer found in more than 2,500 plant species [1;2]. Unfortunately, only few of these species can produce NR with desirable characteristics. NR is used as the raw material for the multiple types of products, such as medical devices, surgical gloves, aircraft, car tires, engineering components, pacifiers, clothes, toys and other [3]. NR possesses several properties that makes it so attractive for industrial use, including high tensile, tear, fatigue strength, ability to stick to itself and to other materials, moderate resistance to environmental damage by heat, light and ozone water, bacterial and viral barrier properties [4].

Currently the majority of NR is collected from tropical tree, member of family Euphorbiaceae $\mathrm{He}$ vea brasiliensis (Muell Arg). The tree is native to rainforests of Amazon region in South America. This includes forests of Brazil, Venezuela, Ecuador, Colombia, Peru, and Bolivia [5]. However, due to the increase of demand for NR, Hevea were introduced to other countries. Currently the main producers of NR are Asian countries, in particular: Thailand with $35 \%$ of worldwide NR supply and Indonesia with $30 \%$ of worldwide NR supply [6]. However, the fact that NR is extracted exclusively from Hevea is a big disadvantage and possesses a big threat for entire rubber industry. An example of such threats is pathogens that can either significantly decrease quantity and quality of extracted rubber, as well as wipe an entire plantation of Hevea [7]. This became possible because of lack of genetic variability that could slow the infection's progression. Strategic pathogens include Microcyclus ulei (South American leaf blight (SALB), Phytopthora spp. (abnormal leaf fall), Oidium Heveae (powdery mildew), Cornyespora cassiicola (Corneyspora leaf fall), Corticium salmonicolor (pink disease), Rigidoporus spp. (white root disease) [8]. Another disadvantage of Hevea exclusive rubber production is its cultivation restrictions. Hevea has very strict environmental growing requirements. This prevents its cultivation on landscapes located outside of certain tropical region, while simultane- 
ously makes it extremely susceptible to climate changes [1]. This characteristic also makes its cultivation a significant part of deforestation problem, since to establish the plantation a corporation or individual farmer must clear the land from forest to plant rubber trees [9]. The cost of Hevea originated NR is another disadvantage. Since latex harvesting is done manually by tapping the bark of rubber tree it is very labour-intensive process [10]. Combine it with fast increase of tapper's age due to unwillingness of younger generation to become tappers since it considered a low-class traditional job and not classified as a profession [11]. Combined with annually increasing demand for NR, increasing shortage of skilled tappers it leads to an increase of Hevea harvested rubber cost [1]. However, Hevea alone cannot satisfy the demand for NR. According to "Statista" website the worldwide demand for NR keeps growing annually as industries keep growing and developing. For example, in 2010 in the world has consumed around 10.7 million tons of NR (cis-1,4-polyisoprene), while in 2019 this number reached up to 13.7 million tons of NR [12]. This means that the shortage of rubber in 2019 were equal to around 100 thousand tones. This situation has sparked an interest of in alternative rubber producing crops. Currently guayule (Parthenium argentatum) and Russian dandelion (Taraxacum kok-saghyz) are the most well-known and promising ones [13].

Scorzonera tau-saghyz a potential rubber crop. Tau-saghyz inhabits stony-rubble slopes of Karatau mountain plateaus at 500-2000 meters above sea level $[14 ; 15]$. Tau-saghyz is a member of Asteraceae family, perennial, dicotyledon plant with diploid set of chromosomes $(n=14)$ [16]. Tau-saghyz was initially discovered during Soviet Union times during exploration of mountains of South Kazakhstan. This discovery pushed the All-Union Research Institute of Rubber and Gutta-Percha to establish research centers in villages Burnyi and Atabayevo as well as a research station in the central part of the Karatau ridge [14]. Tau-saghyz could become a strategic crop for Kazakhstan because its ability to synthesize and store NR. Scorzonera tau-saghyz is one of the plant species capable of synthesizing NR in quantities sufficient to be considered a rubber crop. In Scorzonera tau-saghyz NR is synthesized and stored mainly inside the underground stem (caudex) and root. Previously obtained data on rubber content of tau-saghyz showed that it could accumulate up to $40 \%$ of dry mass of the roots consists of rubber. Plant stores rubber in its roots and underground stem. If the root is damaged latex appears on the surface of the wood in form of milky-white or yellowish-green coloured substance which quickly coagulates on air (Figure 1).

Int. j. biol. chem. (Online)

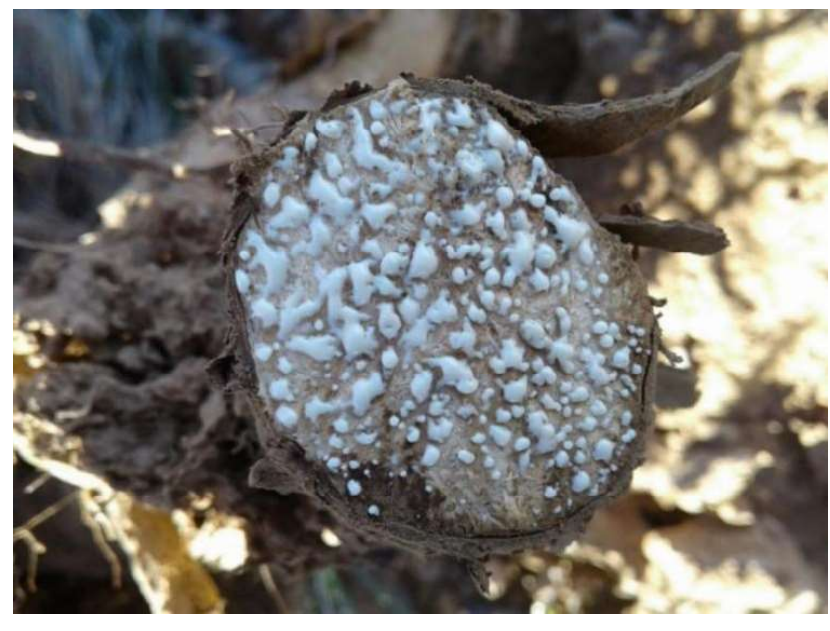

Figure 1 - Latex appearing on the surface of cut root. Photo by Mutalkhanov M., 2019

Unfortunately, the population of tau-saghyz has been reduced drastically during the years of World War II (1941-1945). During this period for the needs of military industry, more than 12 million roots were harvested, dry weight of which were equal to approximately 908 metric tons is to [17]. These events had significant impact on population of tau-saghyz, which was significantly damaged by the end of these years. As result in 1978 Scorzonera tau-saghyz was included into The Red Book of the USSR and further into the Red Book of the KazSSR and Red Book of the Republic of Kazakhstan [14]. There are several variations of tau-saghyz. The most notable ones were identified at following locations: Kaynar-Bastau (eastern part of Karatau mountain), Jelagan-Ata (central part Karatau mountain) and Leontyevka (eastern part of Karatau mountain) [18].

Currently the population of Scorzonera tausaghyz has started to recover. However, there are number of factors limiting its recovery in natural conditions. These factors include its weak competitiveness, low seed germination rate and intensive conversion of the territory into pastures and plantations. Combination of these factors significantly slows down recovery of population both inside and outside of natural reserve [14]. One of the ways to solve this problem is application of microclonal propagation from apical meristem. As well as cultivation at controlled conditions within a laboratory and on a field. As result of such projects population of Scorzonera tau-saghyz started to recover. Currently tau-saghyz is included into the decree of the Government of the Republic of Kazakhstan of October 31, 2006 "On approval of the Lists of rare and endangered species of animals and plants" and is protected by law [19]. The

International Journal of Biology and Chemistry 14, № 2 (2021) 
plant can be found on the territory of Karatau state natural reserve.

Morphology of Tau-saghyz. Scorzonera tausaghyz is a woody semi shrub plant. The height of its aerial part could reach up to $25-40 \mathrm{~cm}$. The aerial part of the plant takes form of a rosette, shaped as squat hemispherical cushions. Compactization of these cushions could either be sparse or mildly dense. On Figure 2 a typical look of $S$. tau-saghyz cushion is presented.

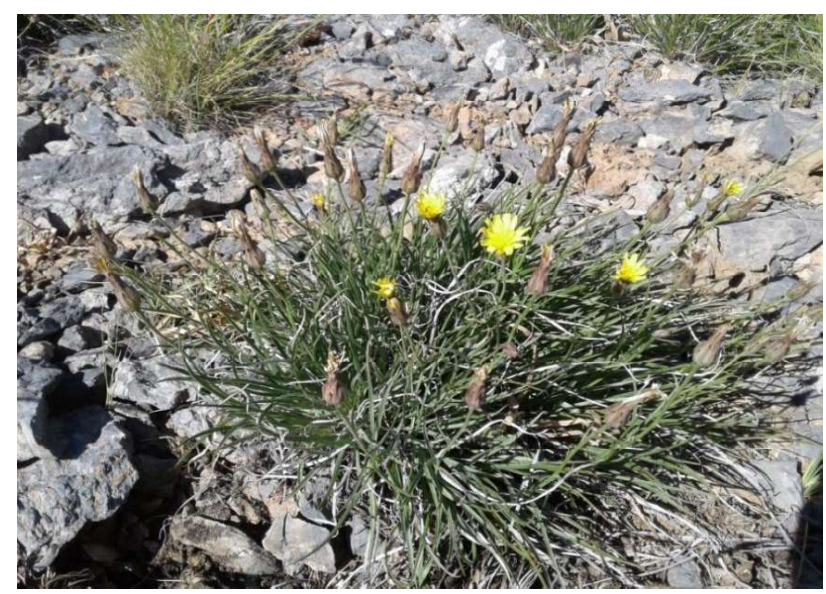

Figure 2 - Aerial part of Scorzonera tau-saghyz. Photo by Mutalkhanov M., 2019

These cushions are made of multiple short, densely branched, thick, woody, perennial branches. These branches typically grow from area close to the root collar. In general, these rosettes reach up to 30 $\mathrm{cm}$. in diameter. However, the environmental conditions in which plant was growing could significantly alter the diameter, sometimes it could reach up to 100 $\mathrm{cm}[20]$.

The stem is covered by multiple dry leaves. The colour of these leaves varies from gray-brown to dark green with weak gloss, the texture of covering leaves is rough. Almost all of the leaves are sedated into deltoid base. Typically, the rosette contains between 6 and 24 leaves. Typically, the colour of leaves is greyish green, ends of the leaves have sharp edge of reddish-brown colour. The surface of the leaf may be either smooth or mildly pubescent. The lower part of the leaf has a distinct furrow on it. The central bigger one forms a distinct keel; the lateral ones are smaller and located along the central. The furrows are white coloured with distinct gloss. Leaves are expanded into an axil shaped like a delta. On the exterior the axil is smooth, cream coloured and glossy. An interior of the axil is densely covered by silky, slightly curly, light-brown, shiny hairs, up to $3-4 \mathrm{~mm}$ long [20]. The rosette's base is approximately $1 \mathrm{~cm}$ wide. There are several rows of scales covering this base. The external scales are $9 \mathrm{~mm}$ long and wide, round shaped but with distinct point at the top, internal ones are up to $3 \mathrm{~cm}$ long, lanceolate and elongated. The scales are semi-transparent, with dark brown coloration. The central vein of these leaves is more prominent, and the multiple (up to 10) lateral veins are less noticeable. They're bare outside, and slightly pubescent inside at the foundation, with a tiny amount of hair [20]. The underground part of the plant (caudex) compared to the short but highly branched aerial part is significantly longer, with scree habitats resulting in highest length of underground stem. The bark of the underground part is bare, with rough texture, and has a dark brown colour. Each branch of caudex ends with a rosette of leaves or sometimes it can end with a flowering shoot $[14 ; 20]$. Caudex has several purposes, for example: nutrients and water storage, nutrients transmission, as well as participation in vegetative reproduction of the plant, which remains the main mean of reproduction. Inside the caudex S. tau-saghyz have a multinucleated tube-like cell called laticifers. In these laticifers occurs the reaction of polymerization, which leads to the synthesis of cis-1,4-polyisoprene or NR.

Rubber biosynthesis. NR is a cis-1,4-polyisoprene polymer that consists of Isopentenyl pyrophosphate (IPP) monomers. IPP is an isoprenoid precursor which acts as an intermediate in the mevalonate (MVA) and in the non-mevalonate (MEP) pathway of isoprenoid precursor biosynthesis. IPP for rubber biosynthesis could either be derived through the MVA pathway occurring in cytosol or through MEP pathway occurring in plastids [8]. Studies performed on Hevea revealed that latex carbon used during rubber biosynthesis does not come directly from photosynthetic apparatus, but from stored carbohydrates like starch [21].

Indication of phonotypical traits could be associated (directly or indirectly) with increased accumulation of rubber is the main goal during the development of commercially viable rubber crop. It's suggested that increased quantities of pigments could have a beneficial effect, due to the increased supply of carbon which further will be used during rubber biosynthesis. 


\section{Materials and methods}

Plant materials. Samples of the leaves, caudices and roots of Scorzonera tau-saghyz were collected by digging from wild fields at Karatau mountains in the Turkestan district. In particular, on the Kurmantas ridge (Figure 3-a) and Kanyon-Teris Akkan (Figure 3-b) in the national park. Samples were collected from May to June 2019.

The samples were collected from the plants growing on two ridges of mountains: south, north and west. The number of samples taken constituted 34 from south and west ridges and 32 from north ridge. Obtained samples were transported to Laboratory of ecological biotechnology at Al-Farabi Kazakh National University (KazNU). To preserve harvested samples during the transportation collected leaves, caudices and roots were stored in liquid nitrogen. After the samples got delivered, they were stored at $-80 \square$ until use.

Pigment extraction and quantification. Determination of pigment quantity were performed using Arnon (1945) method [22]. $1 \mathrm{~g}$ of defrosted leaves were taken and grounded in $5 \mathrm{ml}$ of $90 \%$ acetone using pestle and mortar. Obtained extract were transferred to centrifuged at $5000 \mathrm{rpm}$ for $5 \mathrm{~min}$. After centrifugation complete the supernatant were transferred into clean tubes, while avoiding disrupting the pellet. The examination of the supernatant was performed on spectrophotometer. Light absorption read at wavelength of 663,645 , and $441 \mathrm{~nm}$. Quantity of pigment was calculated using Holm-Wettstein formulas (1.1-1.4):

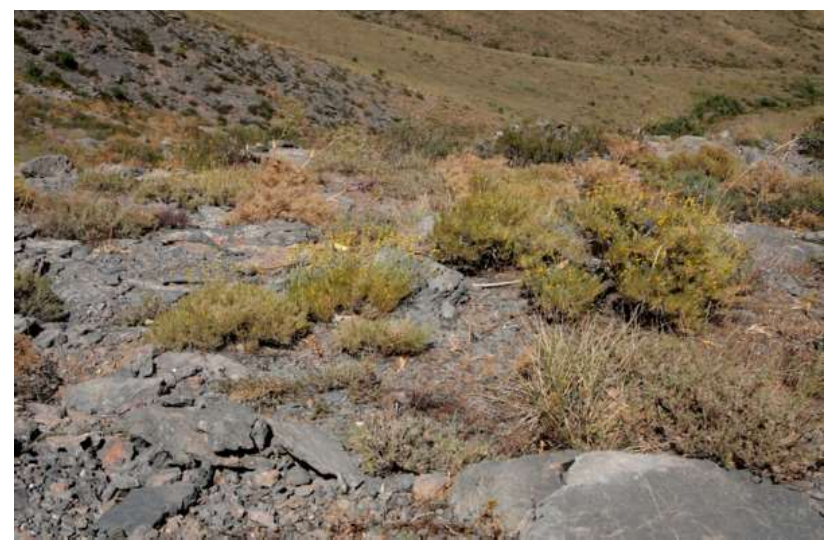

a

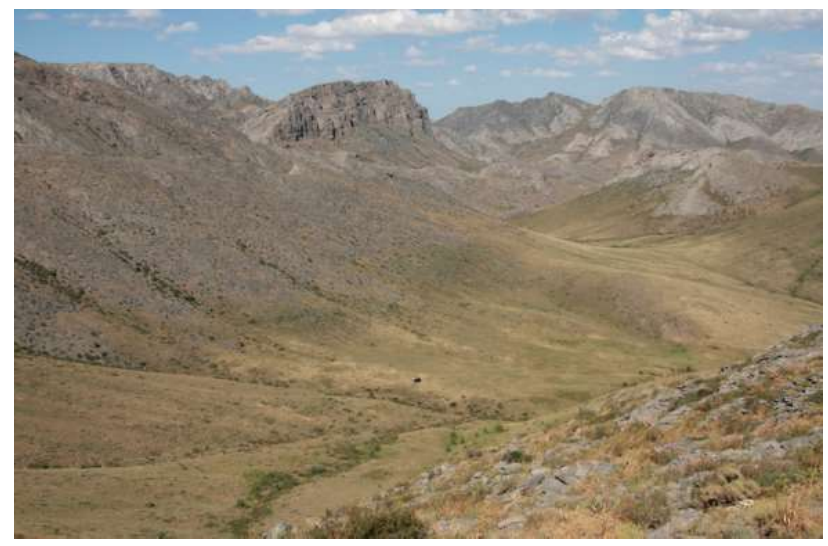

b

Figure 3 - Karatau mountains area where samples taken. Photo by Mutalkhanov M., 2019. Note: $\mathrm{a}$ - Kurmantas ridge; $\mathrm{b}$ - Caniyon-Teris Akkan

$$
\begin{aligned}
& \mathrm{C}_{C h_{\mathrm{A}}}(\mu \mathrm{g} / \mathrm{ml})=9.784\left(A_{662}\right)-0.990\left(A_{644}\right) \\
& \mathrm{C}_{C h_{b}}(\mu \mathrm{g} / \mathrm{ml})=21.426\left(A_{662}\right)-4.650\left(A_{644}\right) \\
& \mathrm{C}_{C h_{a+b}}(\mu \mathrm{g} / \mathrm{ml})=5.134\left(A_{662}\right)-20.436\left(A_{644}\right) \\
& C_{\text {Carotenoid }}=4,695\left(A_{441}\right)-0.268\left(\mathrm{C}_{C h_{a+b}}\right)
\end{aligned}
$$

where:

A662- light absorption at wavelength of $662 \mathrm{~nm}$ A644-light absorption at wavelength of $644 \mathrm{~nm}$ A441 - light absorption at wavelength of $441 \mathrm{~nm}$

Rubber extraction and purification. Root samples washed with running water to clean them of the soil.
After washing, the roots were air dried in the shade. These roots transferred to KazNU where they have been stored at $-80 \square$ for 3 months. The root samples were grinded into powder by mill. Approximately $4 \mathrm{~g}$ of powder is then transferred to Erlenmeyer flask with $50 \mathrm{ml}$ hexane. The remaining hexane were removed by 
IKA RV05 basic rotary evaporator (IKAWerkeGmbH \& Co. KG, Germany) with IKA HP4 basic water bath (IKAWerkeGmbH \& Co. KG, Germany) have been used. After that the remainings were dried in a VD115 vacuum dryer (BINDERGmbH, Germany) at $24{ }^{\circ} \mathrm{C}$ for 22-24 h. All procedures performed at $23-25^{\circ} \mathrm{C}$.

Statistical analysis. The difference in pigment and rubber content between the groups examined using two-tailed t-test. Correlation analysis between pigment and rubber content performed using Pearson correlation. The calculations were performed using Microsoft Excel Add-on XLStat (ver. 2020.4) by Addinsoft.

\section{Results and discussion}

Differences in pigments and rubber content. Determination of pigment content in leaves of Tausaghyz revealed that the content of pigments in leaves strongly depends on location of slope. So, the mean pigment content in leaves from East samples were highest, followed by South and North samples respectively (Table 1). The same pattern observed during determination of carotenoid content. T-test have shown that groups from different slopes .

Table 1 - The results of the t-test analysis of pigments and rubber content between groups

\begin{tabular}{|c|c|c|c|c|c|}
\hline Substance & Groups & $\mathrm{t}_{\text {Observed }}$ & $\mathrm{t}_{\text {Critical }}$ & DF & alpha \\
\hline \multirow{4}{*}{ Chlorophyll-A } & East-North & 3.809 & 1.998 & 65 & 0.05 \\
\cline { 2 - 6 } & South-North & 2.420 & 1.998 & 65 & 0.05 \\
\cline { 2 - 6 } & South-East & 1.376 & 1.998 & 66 & 0.05 \\
\hline \multirow{3}{*}{ Chlorophyll-B } & East-North & 3.902 & 1.998 & 65 & 0.05 \\
\cline { 2 - 6 } & South-North & 1.431 & 1.998 & 65 & 0.05 \\
\cline { 2 - 6 } & South-East & 1.696 & 1.997 & 66 & 0.05 \\
\hline \multirow{3}{*}{ Carotenoid } & East-North & 3.951 & 1.998 & 65 & 0.05 \\
\cline { 2 - 6 } & South-North & 2.200 & 1.998 & 65 & 0.05 \\
\cline { 2 - 6 } & South-East & 1.412 & 1.997 & 66 & 0.05 \\
\cline { 2 - 6 } & East-North & 3.755 & 1.998 & 65 & 0.05 \\
\cline { 2 - 6 } & South-North & 2.296 & 1.999 & 66 & 0.05 \\
\hline \multirow{3}{*}{ Rubber } & South-East & 1.260 & 1.997 & 65 & 0.05 \\
\cline { 2 - 6 } & East-North & 0.280 & 1.998 & 65 & 0.05 \\
\cline { 2 - 6 } & South-North & 0.125 & 1.998 & 66 & 0.05 \\
\hline
\end{tabular}

The t-test showed that $\mathrm{t}_{\text {Observed }}>\mathrm{t}_{\text {Critical }}(3.809>1.998$ with $\mathrm{DF}=65$, alpha $=0.05$ ), which shows a statistically significant difference between East and North with $95 \%$ probability. A similar analysis of the following groups established a significant difference between South and North $(2.420>1.998 ; \mathrm{DF}=65$, alpha $=0.05)$. At the same time, South and East $(1.376<1.998 ; \mathrm{DF}=66$, alpha $=0.05)$ showed no difference between each other. Content of chlorophyllB differed between East and North (3.902>1.998; DF $=65$, alpha $=0.05)$. However, no difference indicated between South-North $(1.431<1.998$; DF $=65$, alpha $=0.05)$ and South-East $(1.696<1.998$; DF $=66$, alpha $=0.05)$. Total chlorophyll content differed between the East-North $(3.951>1.998 ; \mathrm{DF}=65$, alpha $=0.05)$ and South-North $(2.200>1.998 ; \mathrm{DF}=65$, alpha $=0.05)$ slopes. At the same time, South-East $(1.412<1.998 ; \mathrm{DF}=66$, alpha $=0.05)$ showed no difference between each other. Carotenoid content were

Int. j. biol. chem. (Online) different between the East-North $(3.755>1.998 ; \mathrm{DF}=$ 65 , alpha $=0.05)$ and South-North (2.296>1.998; DF $=65$, alpha $=0.05)$ slopes. At the same time, SouthEast $(1.260<1.998 ; \mathrm{DF}=66$, alpha $=0.05)$ showed no difference between each other. Rubber accumulation shown no statistically difference between the groups East-North $(0.280>1.998 ; \mathrm{DF}=65$, alpha $=$ $0.05)$, South-North $(0.125>1.998 ; \mathrm{DF}=65$, alpha $=$ $0.05)$ and South-East $(0.195<1.998 ; \mathrm{DF}=66$, alpha $=$ 0.05). Results show that plants from South and East have significantly higher quantities of pigments compared to North. On the other hand content of rubber showed no difference between the groups.

Correlation analysis of the rubber content and the pigments content. To determine the degree of association between the accumulation of photosynthetic pigments in the leaves and the accumulation of rubber in the roots, the linear correlation coefficient r-Pearson used (Table 2).

International Journal of Biology and Chemistry 14, № 2 (2021) 
Table 2 - The results of the correlation analysis between the pigments content in leaves and the content of rubber in roots in samples from Karatau mountains slopes

\begin{tabular}{|c|c|c|c|}
\hline & \multicolumn{3}{|c|}{ Rubber } \\
\hline Slopes & North & East & South \\
\hline Ch-a & 0.169 & -0.090 & -0.263 \\
\hline Ch-b & 0.094 & -0.088 & -0.286 \\
\hline Ch-a+b & 0.150 & -0.088 & -0.293 \\
\hline Car & 0.225 & -0.098 & -0.099 \\
\hline
\end{tabular}

Data from the correlation analysis between the rubber content in roots and the pigment content in leaves of Scorzonera tau-saghyz shows that rubber content in roots has very weak correlation with all four pigment variants. Among the groups only north, which showed lowest mean quantity of pigments, displayed positive correlation. On the other hand south and east, which showed the higher mean quantity of pigments, displayed negative correlations. However, due to the weak association between pigments and rubber quantities, it is suggested that pigment quantity not associated with rubber accumulation in roots.

Obtained data aligns with data obtained by Thaler P. et al. (2016) [23], who tracked the movement of carbon isotope ${ }^{13} \mathrm{C}$ throughout the body of Hevea, which allowed them to track the distribution of carbon in organism of plant. According to their findings carbon for rubber biosynthesis do not come directly from photosynthetic apparatus. Instead it "accumulated in mixed pool of carbohydrates within the plant". Possible reason for the lack of correlation may be the fact that there is a direct competition for organic compounds between the processes of biomass accumulation and rubber accumulation. Taking into account the fact that rubber is a secondary metabolite, its possible that the accumulation of biomass will be of paramount importance for the organism. Moreover, since the samples of leaves and roots collected during the flowering phase of tau-saghyz, the costly process of rubber formation were suppressed.

\section{Conclusion}

NR is biopolymer used in wide variety of industries. S. tau-saghyz is a plant that can be used as an alternative rubber crop, which in term could have a beneficial effect on economy and industry of the country. During experiment samples of leaves and roots collected from 3 groups of wild plants(South, East, North) undergo the pigment and rubber extraction processes. Results of t-test indicated clear difference in pigment content between North and

Int. j. biol. chem. (Online)
South, East, while non have been indicated between South and East. In case of rubber accumulation. t-test showed lack of statistically significant difference between all three groups.

Pearson correlation analysis showed that all of the pigment variants have very weak correlation with rubber accumulation. Because of that it were considered negligible. Possible reason for it being direct competition for organic compounds between the processes of biomass accumulation and rubber accumulation. Its possible that collection of rubber while plant is in dormant state could increase rubber yield due to the absence of the competition.

Acquired data shows that pigment content cannot be used as a mean to identify plants with high rubber productivity. Researches on other mechanisms are required in order to identify phenotypical traits associated with increased rubber content.

\section{Funding}

The work was financially supported by MES RK within the Project No. AP08053131 Efficient editing of the Scorzonera Tau-Saghyz genome using CRISPR/Cas9 technology to obtain genetically improved plants with an increased content of natural rubber (for 2020-2022 yy).

\section{References}

1 van Beilen J., Poirier Y. (2007) Establishment of new crops for the production of natural rubber. Trends Biotechnol., vol. 25, no. 11, pp. 522-529. https://doi: 10.1016/j.tibtech.2007.08.009.

2 Rasutis D, Soratana K, McMahan C.M., Landis A.E. (2015) A sustainability review of domestic rubber from the guayule plant. Ind Crops Prod., vol. 70. pp. 383-394. doi:10.1016/j.indcrop.2015.03.042

3 Beliczky L. S., Fajen J. (2012) Encyclopaedia of Occupational Health and Safety 4th Edition. Chapter 80 - Rubber Industry. https://www.iloen- 
cyclopaedia.org/contents/part-xii-57503/rubber-industry.

4 Industrial Rubber Goods: The Buyer's Guide. (from July 1, 2020, corrected at July 3, 2019, accessed at July 6, 2021). http://www.industrialrubbergoods.com/natural-rubber.html.

5 Rainforest-Alliance. (from June 24, 2021, corrected at June 29, 2021, accessed at July 3, 2021). https://www.rainforest-alliance.org.

6 Bottier C. (2020) Biochemical composition of Hevea brasiliensis latex: A focus on the protein, lipid, carbohydrate and mineral contents. ADV BOT RES., vol. 93, pp. 201-237. https://doi.org/10.1016/ bs.abr.2019.11.003.

7 Buranov A. U., Elmuradov B. J. (2010) Extraction and Characterization of Latex and Natural Rubber from Rubber-Bearing Plants. J. Agric. Food Chem., vol. 58, no. 2, pp. 734-743

8 Cao X., Yan J., Lei, J., Li, J., Zhu, J., Zhang, H. (2017) De novo Transcriptome Sequencing of MeJA-Induced Taraxacum kok-saghyz Rodin to Identify Genes Related to Rubber Formation. Sci. Rep., vol. 7. https://doi.org/10.1038/s41598-017-14890-z.

9 Warren-Thomas E.M., Edwards D.P., Bebber D.P. et al. (2018) Protecting tropical forests from the rapid expansion of rubber using carbon payments. Nat. Commun., vol.9, pp. 911. https://doi. org/10.1038/s41467-018-03287-9.

10 Mooibroek H., Cornish K. (2000) Alternative sources of Natural Rubber. Appl. Microbiol. Biotechnol., vol. 53, pp. 355-365. https://doi. $\operatorname{org} / 10.1007 / \mathrm{s} 002530051627$.

11 Hazir M., Kadir R., Gloor E., Galbraith D. (2017) Effect of agroclimatic variability on land suitability for cultivating rubber (Hevea brasiliensis) and growth performance assessment in the tropical rainforest climate of Peninsular Malaysia. Clim. Risk Manag., vol. 27, pp. 100-203. https://doi. org/10.1016/j.crm.2019.100203.

12 Statista. (from June 29, 2021, corrected at July 2, 2021, accessed at July 4, 2021). https://www. statista.com/topics/3268/rubber/\#dossierKeyfigures.

13 Cornish K. (2011) Similarities and differences in rubber biochemistry among plant species. Phytochemistry., vol. 57. - pp. 1123-1134. https:// doi.org/10.1016/s0031-9422(01)00097-8.

14 Boguspaev K.K., Adil'baev Zh.A., Faleev D.G., Zhanataev Sh.A., Turasheva S.K., Sambetov K.K. (2013) Perspektivy razrabotki tehnologij vosstanovlenija populjacii rastenij tau-sagyza (Scorzonera tau-saghyz (Lipsch. et Bosse) v Karatauskom gosudarstvennom prirodnom zapovednike [Prospects for the development of technologies for restoring the plant population of tau-sagyz (Scorzonera tau-saghyz (Lipsch. et Bosse) in the Karatau State Nature Reserve]. Vestnik KazNU. Serija jekologicheskaja. vol. 2, pp. 38. https://pandia.ru/text/80/317/71142.php.

15 Plants For A Future Database (from June 16, 2021, with corrections at June 20,2021, accessed at June 26, 2021). https://pfaf.org

16 Bordbar F., Makki P., Alifarsangi F. (2019) Karyotype Investigations in Iranian Scorzonera tortuosissima and S. intricata, Asteraceae. Cytologia, vol. 84, no. 1, pp. 69-72. https://doi.org/10.1508/cytologia.84.69.

17 Arias M., Hernandez M., Remondegui N., Huvenaars K., van Dijk P., Ritter E. (2016) First genetic linkage map of Taraxacum koksaghyz Rodin based on AFLP, SSR, COS and EST-SSR markers. Sci. Rep. vol.6. https://doi.org/10.1038/srep31031.

18 Bondarenko P. V., Tarakanov S.G. (1941) Tau-sagyz. Priemy vyrashhivanija v Srednej Azii [Tau-sagyz. Cultivation techniques in Central Asia]. Tashkent: AN SSSR, Uzbekskij filial. Izdatel'stvo UzFAN.

19 Collection of acts of the President of the Republic of Kazakhstan and the Government of Republic of Kazakhstan. (2006) "On approval of the list of environmental protection objects of special ecological, scientific and cultural significance" . vol. 40, pp.444.

20 Kul'tijasov M.V. (1938) Tau-Sagyz i vvedenie ego v kul'turu [Tau-Sagyz and its introduction into culture]. Moskva: Izdatel'stvo Akademii nauk SSSR. pp. 45-51

21 Men, X., Wang, F., Chen, G. Q., Zhang, H. B., \& Xian, M. (2018). Biosynthesis of Natural Rubber: Current State and Perspectives. Int. J. Mol. Sci., vol. 20, no. 1, pp. 50. https://doi.org/10.3390/ ijms20010050.

22 Yavorska N., Vorobets N. (2019) Photosynthetic Pigments in Shoots of Vaccinium corymbosum L. (Cv. Elliott). Agrobiodivers. improv. nutr., health life qual., vol. 3. pp. 93-100. https://doi.org/10.15414/ agrobiodiversity.2019.2585-8246.093-100.

23 Thaler P., Duangngam O., Kasemsap P., Sathornkich J., Chayawat C., Satakhum D., Priault P., Desalme D., Chantuma P.,Ghashghaie J., Epron D. (2016) The source of latex. Tracing carbon from leaf photosynthesis to latex metabolism in rubber trees using carbon sTable isotopes. CRRI and IRRDB International Rubber Conference. Cambodia, P. 260-268. 